\title{
Actors in private food governance: the legitimacy of retail standards and multistakeholder initiatives with civil society participation
}

\author{
Doris Fuchs $\cdot$ Agni Kalfagianni $\cdot$ Tetty Havinga
}

Accepted: 13 August 2009/Published online: 19 September 2009

(C) The Author(s) 2009. This article is published with open access at Springerlink.com

\begin{abstract}
Democratic legitimacy is rarely associated with private governance. After all, private actors are not legitimized through elections by a demos. Instead of abandoning democratic principles when entering the private sphere of governance, however, this article argues in favour of employing alternative criteria of democracy in assessments. Specifically, this article uses the criteria of participation, transparency and accountability to evaluate the democratic legitimacy of private food retail governance institutions. It pursues this evaluation of the democratic legitimacy of these institutions against the background of their ambivalent impact on the sustainability of the global agrifood system. The paper refers to a range of cases of private retail standards with different governance structures and substantial foci to illustrate its argument.
\end{abstract}

Keywords Democratic legitimacy - Food standards . Private governance $\cdot$ Retailers $\cdot$ Sustainable development

\section{Introduction}

The objective of this paper is to evaluate the democratic legitimacy of private food governance institutions in the

D. Fuchs $(\square)$

Chair of International Relations and Development Policy,

Scharnhorststr. 100, 48151 Münster, Germany

e-mail: Doris.Fuchs@uni-muenster.de

\author{
A. Kalfagianni \\ Department of International Relations and European Integration, \\ Breitscheidstr.2, 70174 Stuttgart, Germany \\ T. Havinga \\ Institute for the Sociology of Law, Radboud University \\ Nijmegen, PO Box 9049, 6500KK Nijmegen, The Netherlands \\ e-mail: T.Havinga@jur.ru.nl
}

retail sector. We concentrate on private retail standards because this is a form of private food governance that has expanded dramatically over the last couple of decades. Moreover, previous studies have found that private retail governance is associated with highly ambivalent implications for the sustainability of the global agrifood system (Fuchs et al. 2009). Accordingly, this form of governance urgently needs to be evaluated regarding its democratic justifiability.

The paper starts from the recognition that global food and agricultural governance is increasingly being created not only by (inter)governmental actors but also by private actors. In the food sector, as elsewhere, next to traditional command-and-control, alternative forms of regulation are being explored, such as self-regulation, co-regulation, management-based regulation and other private systems of governance (Aalders and Wilthagen 1997; Braithwaite 1982; Coglianese and Lazer 2003; Furger 1997; Gunningham and Sinclair 1999; Hutter 2001:9-10). In these new forms of regulation, private actors are assuming pivotal roles in terms of rule-making, monitoring compliance, and enforcement. Food industry and retail corporations, in particular, have become key players in the governance of the global food system through the creation of governance institutions such as private standards, corporate social responsibility initiatives (CSR) and public-private or private-private partnerships (PPPs).

This transition from public to private regulation gives rise to important new theoretical and political concerns of legitimacy (Newman 2001; Kersbergen et al. 2001) and challenges existing conceptualisations of regulation (Black 2002; Sinclair 1997). Public regulation is considered legitimate because of democratic decision-making procedures on rules, implementation, monitoring and enforcement that are meant to safeguard the proportionality of 
rules and measures, inclusion of all relevant interests and redress procedures for victims. Most importantly, however, public regulation is legitimised through its roots in decisions taken (through representatives) by the general public.

This positive evaluation of the legitimacy of public governance has to be taken with a grain of salt, though. Legitimacy chains become longer and are more loosely defined if (elected) governments nominate bureaucrats to represent them in international negotiations and organizations. Even more importantly, public regulation in the international realm frequently takes on the character of a pursuit of "private" interests with governments trying to advance the interests of their country (or segments of its population or economic actors) rather than that of the global population, as Conzelmann and Wolf (2008) have convincingly argued. In consequence, when assessing the democratic legitimacy of private governance in this paper, we are not meaning to imply that public governance is definitely unassailable from this perspective and not worthy of inquiry. In this paper, however, we explicitly focus on the democratic legitimacy of private governance because we consider it a highly relevant phenomenon in today's global food governance which is likely to cause substantial social transformations and a redistribution of income and wealth.

Private rules in the form of standards have far reaching consequences affecting a wide range of actors, such as consumers and suppliers across the globe. As shown by a growing number of studies, the implications of private food governance institutions on the sustainability of the global food system are ambivalent, if we define sustainability as including the dimensions of food safety, environmental well-being, and farmers' incomes. These implications may tend to be positive in some aspects such as the food safety in developed countries but extremely negative in others (Barrientos et al. 2001; Fuchs et al. 2009; Van der Grijp et al. 2005). Especially in developing countries, a trend toward the marginalisation of small farmers and retailers and subsequently an increase in economic inequality due to the expansion in private retail standards can be observed. The latter aspect derives from the situation that these private food standards constrain market access (Busch 2000). The purchasing power of private food actors, in particular today's supermarket chains, makes private standards obligatory for any actor who wants to participate in the (global) market (Fuchs et al. 2009; Havinga 2006).

Our objective in this article, therefore, is to inquire into the democratic legitimacy of private retail food governance. In pursuit of this objective, we apply the criteria of participation, transparency and accountability proposed by Porter and Ronit (2010) in an evaluation of a range of institutions of private retail food governance playing a prominent role in the global agrifood system today. The article proceeds as follows. The next section provides the empirical background to our analysis. It delineates the rise in private retail food governance, presents prominent examples of relevant standards and initiatives, and sketches the ambivalent implications of private retail food governance for the sustainability of the global agrifood system. Then, section three turns to the question of democratic legitimacy and introduces the concepts of participation, transparency and accountability as criteria for assessing the democratic legitimacy of private (retail food) governance. The section also scrutinizes and dismisses alternative criteria, in particular output legitimacy. Section four pursues the empirical analysis of the democratic legitimacy of private retail food governance on the basis of the criteria developed in section three. Finally, section five concludes our article by summarizing our findings and delineating their implications for research and policy.

\section{Background: the rise of private retail food governance and the sustainability of the global agrifood system}

In today's global food governance, private actors, in particular corporations, play a larger role than ever before (Clapp and Fuchs 2009). In particular, they have become rule-setters rather than rule-takers and are deciding, implementing, monitoring and enforcing rules and regulations to an increasing extent. Such "private governance" can take a variety of forms ranging from Corporate Social Responsibility initiatives to self-regulation to co-regulation (e.g. Public-Private Partnerships) and may encompass a wide variety of instruments such as voluntary and cooperative agreements, codes of conduct, corporate reporting, as well as accounting and self-auditing. As one of the key developments in recent years, big supermarket chains have developed initiatives to ensure a certain quality of retail food products by committing suppliers to a specified set of standards. Importantly, private governance institutions, in general, and private retail food governance institutions, in particular, frequently tend to acquire a de facto compulsory role despite their de jure voluntary nature (Blowfield 2005). By adopting such standards, private food companies and especially retail corporations can constrain market access and thereby basically force suppliers to accept them (Busch 2000; Fulponi 2006; Havinga 2006). ${ }^{1}$ Table 1 provides a brief summary of some prominent institutions of private retail food governance today.

\footnotetext{
${ }^{1}$ In consequence, the term "self-regulation" under which these standards are being discussed in the literature is highly misleading. The standards tend to have significant implications for a large group of stakeholders and impose costs on suppliers, in particular.
} 
Table 1 Prominent private retail food standards and initiatives

The British Retail Consortium Global Standard for Food Safety (BRC) was created in 1998 in order to evaluate the manufacturing of retailers' own brand products. It delineates more than 250 requirements including comprehensive norms for food safety and quality schemes, products and process management as well as personal hygiene of personnel. In 2002, a Packaging Standard was published, followed by a Consumer Products standard in 2003 and finally the BRC Standard for Storage and Distribution in 2006. The last standard addresses companies' storage and/or distribution of food, consumer goods and packaging materials. Each of these standards is revised and updated at least every 3 years. For most UK and Scandinavian retailers, BRC certification is required in order to consider business with suppliers (http://www.ceres-cert.com/en_brc.html, 24-11-2008)

The International Food Standard (IFS) is a standard developed by retailers and wholesalers to ensure the safety of own-brand products. It covers common internationally accepted audit standards with the aim to improve safety for the consumers. IFS was initiated in 2002 by German food retailers from the primary association of retailers HDE (Hauptverband des Deutschen Einzelhandels). In 2003, French food retailers (and wholesalers) from the FCD (Fèderation des entreprises du Commerce et de la Distribution) joined the IFS Working Group. The development of the current version of IFS Food, (version 5) is a collaboration of three retail federations from Germany, France and Italy. Retailers from Austria, Poland, Spain and Switzerland also support IFS as their food safety standard. The IFS Food standard deals with processing of food and contains 250 requirements divided over 5 chapters. Next to production process (product specifications, pest control, traceability), management responsibility (e.g. corporate policy), quality management system (HACCP, recordkeeping), resource management (personnel hygiene) and measurements and improvements (internal audit, product recall), the standard also contains an audit protocol

Safe Quality Food (SQF) is a food safety and quality certification program for primary production (SQF 1000) and for food manufacturing and distribution (SQF 2000) owned by the Food Marketing Institute (FMI). The FMI membership represents three-quarters of all retail food stores in the US and 200 companies from over 50 countries. The SQF program was developed in 1994 by the West-Australian Department of Agriculture and sold to American FMI in 2003. SQF is designed as a food safety program and incorporates product quality. Certification is annual at three levels: food safety fundamentals (only for low risk products), certified HACCP food safety plans and comprehensive quality management systems development. After achieving level 3 a certified supplier is authorized to use the SQF certification trademark. 'Responsible environmental practice' and 'responsible social practice' are optional modules for suppliers 'whose markets require additional assurances of responsible environmental and social practice'

The Global Food Safety Initiative (GFSI) was initiated in 2000 by a group of international retailers in order to agree on globally accepted food safety standards. The initiative sets baseline requirements for food safety standards and intends to improve efficiency costs throughout the food chain. Its central aim is to strengthen consumer confidence in food bought in retail outlets. By now, four food safety standards have been benchmarked to be in compliance with the GFSI Guidance Document: BRC, Dutch HACCP, IFS, and SQF. GFSI's aim is to have all products sold meet this standard. In 2006, a survey of the world's leading supermarkets found that 75-99\% of food supplies sold by them are certified against a GFSI benchmarked standard (Fulponi 2006)

The Global Partnership for Good Agricultural Practice (GlobalGap) (known as EurepGap until 2007) was developed in 1997 by a group of European retailers. While initially only applying to fruits and vegetables, it now covers meat products and fish from aquaculture as well. Completion and verification of a checklist consisting of 254 questions is required in order to acquire Global-Gap certification. This checklist is divided into 41 "major musts", 122 "minor musts" as well as 91 recommendations ("shoulds"). Traceability and food safety are covered by major must practices while minor musts cover animal welfare issues and environmental concerns in the context of human health, e.g. release of toxins. Environmental conservation practices fall in the category of recommendations

The Marine Stewardship Council (MSC) is a label for sustainable fishery, created in 1997 as a result of an agreement between Unilever and the WWF. The idea behind MSC is to address world-wide decline in fish stocks by awarding sustainably managed fisheries with a certification and a label that could be affixed to retail products (Ponte 2007:161). The standard is based on 3 principles (maintenance of the target fish stock, minimal environmental impact and effective management) and 31 performance indicators. It can be applied to a wide range of fisheries found across the world coasts, oceans and freshwater bodies (Leadbitter et al. 2006). At the moment, MSC aims at specific fisheries rather than species that could come from multiple fisheries and does not cover aquaculture (Iles 2007). Moreover, it is currently quite small in its fishery coverage and is mostly active in Europe but its endorsement by major retailers is expected to change this situation in the future (Iles 2007)

The Ethical Trading Initiative (ETI) was formed in 1998 by UK trade union representatives of the Trade Union Congress (TUC), the International Textile Garment and Leather Workers' Federation (ITGLWF), the International Confederation of Free Trade Unions (ICFTU), and of NGOs, such as Oxfam and CAFOD (Hughes 2001: 422). UK supermarkets participated in the initiative since its inception (Smith and Barrientos 2005) and currently all but one of the major British supermarkets are part of the initiative (http://www.ethicaltrade. org/Z/abteti/who/memb/list.shtml\#co). ETI aims to develop an agreed baseline code of conduct covering employment conditions among companies, unions and NGOs, and examining how systems of monitoring and verification can be established on the basis of ILO core conventions and UN human rights' standards. As a UK initiative, its ultimate goal is to ensure that the working conditions of workers producing for the UK market at least meet international labour standards. ETI is a code of conduct applying to food products as well as to other products such as clothing. Scholars note that the ETI should be distinguished from fair trade or alternative trade in that it does not only cover small producers and it does not carry a specific seal of approval, although companies can advertise it if they want to (Smith and Barrientos 2005). Rather, it is based on a company applying a code to its suppliers in the same way as it applies other conditions of supply covering production and product specification (ibid.) 
Given the proliferation of private governance institutions in the area of agriculture and food, their implications for the sustainability of the global agrifood system become crucial. As previous research has found, however, these impacts differ in terms of the dimensions of sustainability considered, i.e. food safety, environmental sustainability, social sustainability, and in terms of the distribution of target group considered, i.e. consumers in developed or developing countries (Barrientos et al. 2001; Fuchs et al. 2009; Van der Grijp et al. 2005). ${ }^{2}$

Most private retail food standards address issues of food safety, which accordingly has improved in the food chain. ${ }^{3}$ These positive effects exist mainly for consumers in the industrialized countries and perhaps wealthy consumers in developing countries, however. While optimistic observers note that higher standards for export markets can lead to spillover effects for domestic food safety in developing countries (Jaffee and Henson 2004), critical scholars report that the new retail standards lead to an increasing gap in quality between export and domestic food products (Van der Grijp et al. 2005).

Environmental dimensions of sustainability tend to play a much less prominent role. Retailers are increasingly under pressure to improve at least their environmental performance, of course. Yet, many private standards evaluating retail environmental performance cover only particular goods or companies and do not apply to the sector as a whole (Lang and Barling 2007). Moreover, food retail standards - to the extent that they cover environmental issues at all-address selected elements of environmental protection only, often determined by visibility and marketing qualities for consumers in the North. Of the initiatives presented above only the MSC awards environment a truly prominent role. For other initiatives claiming to pay significant attention to environmental issues as well, such as the GlobalGap, most specifications for environmental conservation are recommendations (see GlobalGap 2008) and non-compliance does not always prevent certification. ${ }^{4}$ More importantly, the emphasis on

\footnotetext{
${ }^{2}$ One can also differentiate sustainability implications for wealthy and poor consumers in developed and especially developing countries.

${ }^{3}$ Quality has not necessarily improved in parallel, however, as the schemes do not address questions of distance travelled and its implications, for instance. Due to these distances, fruits and vegetables are picked early from the field and need to be artificially gassed to ripe, for example. Moreover, the need to have strong varieties which will survive the early harvest and transport and have a long shelf-life frequently creates products end up "relatively tasteless, nutritionally weak" (Robison 1984: 289). At the same time, quality standards assure that at least some level of quality is maintained, however.

${ }^{4}$ In GlobalGap, for major norms $100 \%$ compliance is compulsory, whereas for minor norms this is 95\%. Recommendations are
}

various sustainability issues within the GlobalGap initiative has gradually decreased from its launch until today (Van der Grijp et al. 2005). ${ }^{5}$

The social dimension of sustainability, even if formally included in mainstream retail standards, receives the least attention (e.g. GlobalGap). While some standards address issues of worker welfare, other social implications, in particular the income and well-being of farmers in developing countries, are left out. ${ }^{6}$ This is particular noteworthy, as these implications are significant indeed. Critical observers associate the proliferation of private retail standards with dramatic income losses and restrictions in market access for small farmers and enterprises, who cannot afford the high implementation costs (Brown and Sander 2007; Ponte 2007). ${ }^{7}$ Even significant efforts such as the ETI fail to recognize crucial societal issues, such as the different priorities for female workers and farmers stemming from the gendered nature of women's obligations to meet domestic and household commitments as well as their employment related responsibilities (Pearson 2007). In sum, private retail food standards are creating trends in employment and income that result in highly uneven and unequal development in the producing countries and regions and imply the degradation of social well-being for a substantial share of the population there (Van der Grijp et al. 2005).

To summarise, private retail food governance tends to have positive effects on food safety and some quality. With regard to developing countries, however, this is limited to food products for export markets. Likewise, private food governance can foster some environmental improvements, although not as systematically and comprehensively as one would desire. What private food governance does not foster

Footnote 4 continued

inspected but are not a prerequisite for the granting of a GlobalGAP certificate (Van der Grijp 2008, p. 122).

5 There are other examples with more ambitious goals, such as Farm Biodiversity Action Plans (Sainsboury's for premium fresh produce suppliers), conservation plans linked to FWAG (Tesco's Natures Choice), and the development of additional audit requirements for the Assured Produce Scheme linked to the LEAF audit (Waitrose's LEAF Marque Brand) on the environmental side (Baines 2005). Yet, these standards have an extremely small market share.

${ }^{6}$ Similarly, capital concentration in the retail sector and the global expansion of the operations of the large retail chains are threatening the livelihoods of smaller local retailers as well. This trend is particularly recognizable in regions currently targeted by expansion strategies of retail corporations such as Eastern Europe and Asia.

7 Reardon et al. (2001) report, for instance, that thousands of small dairy operations have gone out of business in the past five years in the extended Mercosur area, because the new quality and safety standards for milk and milk products implied large investments in equipment and buildings and coordination and management. Likewise, NGOs have pointed out that hundreds of thousands of small farmers in Africa are losing or will lose their living in the wake of the implementation of the GlobalGap standards (ActionAid 2005). 
and in fact tends to worsen, however, is the aspect of the social sustainability of the global agrifood system. It is due to these costs, which private retail food governance imposes on the sustainability of the global agrifood system, in particular, that its democratic legitimacy needs to be assessed.

\section{The democratic legitimacy of private food retail governance}

Any attempt to offer a democratic assessment of private governance with traditional notions of democracy will fail as fundamental democracy requirements are violated. Retailers, as any other private actor, are not democratically elected and cannot be held responsible by a relatively homogenous demos, since such a public rarely exists at the global level (Brühl 2002). Instead of abandoning democratic principles when entering the global private sphere, however, we argue in favour of moving away from the domestic analogy and adopting alternative criteria for democratic checks and balances (see also Keohane 2006).

Different interpretations of democracy beyond the state can be identified in the literature. The concepts of "cosmopolitan democracy" (Held 1995) or "discursive democracy" (Dryzek 1990), for instance, offer useful insights for democratic forms of global governance based on notions of global citizenship and discursive practices. Yet these approaches also suffer from a number of shortcomings that make their applicability in the cases examined here problematic. More specifically, the emphasis on private actors, especially business, is often lacking and they tend to be too philosophical to allow for the identification of concrete democratic challenges (Porter and Ronit 2010).

We evaluate the democratic legitimacy of private food retail governance institutions using the criteria of participation, transparency and accountability (Schaller 2007). These three dimensions are widely recognised values and offer strong analytical advantages in the study of private institutions from a democratic perspective (Porter and Ronit 2010). Moreover, they are well suited to study highly complex environments that are associated with transnational corporate activities, and new modes of democratic policy-making evolving alongside traditional institutions (ibid.).

Participation should include all the actors who are potentially affected by the decisions to ensure their autonomy under law, according to procedural arguments. At the most fundamental level, participation requires access to information and decision-making. Three broad categories of actors can be involved in private retail food governance: state actors, business actors and civil society organisations. These represent the actors directly or indirectly affected by the relevant regulations and standards. Private food governance institutions affect a wide variety of stakeholders ranging from the farmer to the consumer. Business and the general public, or civil society organizations as the representatives of the latter, are those actors directly affected by private food governance. State actors are indirectly affected (except for the case of coregulation in the form of public-private partnerships) as private regulation always interacts and sometimes interferes with public regulation and in so far as the private regulation has consequences for the need of state intervention. $^{8}$ With respect to business actors, one needs to differentiate between retailers and food producers and processors in this respect, as well as consider those business actors providing services to the industry such as certification and auditing companies. With regards to civil society, environmental and development NGOs as well as labour organisations are typical representatives. Next to the type of actors involved, attention needs to be paid with respect to their region of origin, when assessing the democratic legitimacy of private retail food governance institutions. Specifically, one needs to consider the distribution in decision making power between representatives of the South and those of the North. ${ }^{9}$

We evaluate participation as a criterion for the legitimacy of private retail food governance in terms of the participatory roles awarded to the different groups by a given governance institution. In our evaluation, we concentrate on the actors directly affected by the institutions, i.e. the different types of business actors as well as civil society representatives and their region of origin. These actors may be given decision-making power in the central governing organ of the private governance institution. They may be provided with access to meetings of this organ, but have only a consulting status. Finally, they may be excluded from the meetings altogether. Participation as a criterion for the democratic legitimacy of a private food governance institution would require that all of the groups affected by that institutions need to receive decisionmaking power in the central governing organ of the institution.

Transparency refers to the provision of timely, reliable and comprehensible information on the governance and

\footnotetext{
$\overline{8}$ The private regulation may increase/decrease wealth in certain sectors of society, for instance, leading for more or less need for welfare provisioning by the state.

9 This aspect becomes somewhat difficult, when talking about developmental NGOs, of course. Frequently, their stated objective is the representation of the interests of the population or specific segments of the population in developing countries, while their decision-making organs are dominated by individuals from developed countries. This difficulty should not lead to a neglect of the question of the distribution in decision making power between North and South in a private food governance institution, in general.
} 
performance characteristics of the standards. It is an important dimension of legitimacy because it enhances public scrutiny and visibility in complex environments, thereby also strengthening meaningful participation and ensuring accountability. Transparency can be internal and external, i.e. information available only to members and information available to the general public. We are specifically interested in the external aspect of transparency examining access to information by stakeholders not participating in the ownership of the standards but directly or indirectly affected by them. Such stakeholders include, for instance, the "governed", i.e. farmers and farmer workers, as well as civil society organisations and the general public.

We evaluate transparency on the basis of information provided on the standards' websites, as well as access to conferences and other meetings organised by the standard owners (see also Schaller 2007). Governance related transparency means access to information on decisionmaking structures and processes. Performance related transparency means access to information on the associated (public) benefits gained by the implementation of the standard, for instance, in the context of food safety and/or environmental sustainability. We also reflect on the standards' issue coverage as selective transparency can obscure the visibility of the standards' full range of impacts, thus fostering a partial appraisal of the standards' role in the agri-food system. The focus on food safety, for instance, can shift interest away from sustainability "externalities" along the supply chain.

We consider transparency timely when there is reference to recent events, projects etc. as well as when critical information is available before important decisions have been made. Reliability of information depends on the existence of external mechanisms of information control instead of simply self-reporting activities on a voluntary basis. Regarding comprehensibility, given the global coverage of standards and the diverse audiences affected by them, we consider the language of communication of information and the level of technical detail and discourse important parameters. We expect differences in the visibility of standards between Northern and Southern publics, however, as transparency is also subject to technological and financial constraints.

Finally, accountability is a fundamental prerequisite for the exercise of democratic control over governance institutions. Accountability is needed in terms of the internal and external auditing of regulations and standards, and more crucially, in terms of the relationship between the governance institution and the affected stakeholders or the general public. It is the fundamental idea of democratic governance that the affected public should be able to hold decision-makers accountable and "vote" them out of office if a given governance institution performs badly.
In liberal democracies, accountability is ensured through mechanisms of representation, rights of legislators to scrutinise and hold public servants accountable, and public answerability of governmental agencies and officials (Gulbrandsen 2008). Public law, however, is not the only source of accountability. In private governance arrangements, internal accountability is ensured through delegations, e.g. corporate CEOs are responsible to their board of directors who are responsible to stockholders (Keohane 2006). More difficult, though not impossible, is to achieve external accountability, where organizations are held accountable not to those who delegated power to them but to those affected by their decisions. In that context, Furger (1997, p. 449) underlines the "role of intermediary organisations as institutions that are particularly suited to develop and maintain standards of accountability". In other words, actors, whom those governed by an institution trust in terms of the neutrality of perspective and expertise, can be awarded the role of operating the instruments in place to hold the "governors" accountable. In relation to the discussed examples of private governance, intermediary organisations who could potentially play such a role are auditing organisations and certification bodies, for example.

Auditing or third party certification mechanisms provide checks and balances regarding the standards' violation codes but they do not necessarily extend this accountability to farmers and farm workers (see also Schaller 2007). Moreover, these mechanisms do not cover the public affected by the externalities of the standards, for instance, in their environmental and particularly social dimensions. In consequence, additional mechanisms of intervention that can strengthen the external accountability of the standards are required.

Accordingly, we evaluate internal accountability in terms of the existence of responsibility mechanisms from board members to their constituencies and civil society representatives to their organisations. We evaluate external accountability in terms of the presence of an independent and trusted actor, who is awarded the authority and instruments to regularly conduct checks of the performance of the given private retail food governance institution. Moreover, we define the ability of the affected public or its representatives to intervene and adjust the governance institution as a prerequisite for accountability.

Having defined participation, transparency, and accountability, in this manner, we are setting high benchmarks for our evaluation of the democratic legitimacy of private retail food governance, of course. One can easily point out that public international governance frequently does not completely fulfill these requirements either. Again, our aim in this analysis is not to paint a black and white picture of private versus public food governance. 
Rather, we consider private food governance to be such an important phenomenon that we want to explore its democratic legitimacy in its own right. Specifically, we want to identify areas in which private retail food governance performs well from the perspective of democratic legitimacy and areas in which notable problems exist. Moreover, we want to compare this situation against different types of private retail food governance institutions. Only on the basis of such insights can one then discuss ways to improve the democratic legitimacy of private food governance.

Why not output legitimacy?

Before we proceed with the analysis, a note has to be made regarding alternative concepts of evaluating the democratic legitimacy of private governance. Some scholars have suggested the concepts of input, output and throughput legitimacy here (Erman and Uhlin forthcoming; Scharpf 1998). Input legitimacy refers to the criterion of participation, while throughput legitimacy tends to be interpreted as combining aspects of transparency, responsiveness, and fairness of the procedures of a governance institution. Thus, the concept of input legitimacy is covered by our criteria as well. The problem with the concept of throughput legitimacy is the combination of the aspects of transparency and responsiveness (or in our terms accountability), as well as of positive and normative criteria, which inhibit its systematic empirical application. The major problem, however, exists with respect to the concept of output legitimacy, especially as it frequently is used as a justification for the democratic legitimacy of private governance, but applied in very sweeping and superficial terms. This handling of the concept and its empirical application serves to hide its fundamental problems. Yet, these problems exist and need to be named.

The concept of output legitimacy refers to the notion that legitimacy can arise from the ability to provide results rather than from the existence of participatory norms and procedures or the presence of checks and balances (Scharpf 1998). Put differently, the "effectiveness" of a governance institution functions as a source of legitimacy, here. To the extent, then, that private governance is as or more effective than public governance, it could be considered as having output legitimacy.

It is extremely difficult if not impossible to assess the effectiveness of a private governance institution, however. Assessing effectiveness requires the definition of objectives, against which the performance of the governance institution can be evaluated. Yet, different stakeholders will tend to define different objectives, or even similar objectives differently. As we argue below, different actors in the food chain tend to define very different sustainability criteria, for instance. In other words, the objectives of a private governance institution cannot be consensually defined without a prior process of discussion and negotiation. Accordingly, effectiveness cannot be objectively measured without such a process either. In other words, a participatory, transparent and responsive deliberative process to define the objectives, involving all affected stakeholders, remains necessary, which returns us to the criteria of participation, transparency and accountability defined above. $^{10}$

Applying these general ideas to the topic private retail food governance, we find the following. Different stakeholders define the objectives of private retail standards very differently, even though they all tend to broadly refer to sustainability objectives (Kalfagianni 2006). Retailers themselves will define sustainability in terms of food safety (narrowly defined) and therefore argue that traceability schemes will allow an effective achievement of this objective. Environmental, consumer, and animal welfare organisations will add environmental and/or animal welfare objectives to the sustainability dimensions required. Accordingly, retail standards focussing on traceability will fail to provide the desired output in their view. Small farmers in developing countries surely would want to add the aspect of farmer income and rural livelihoods to the sustainability. However, they tend not to get asked (see below).

\section{Assessing the democratic legitimacy of private retail food governance}

In order to assess the democratic legitimacy of private retail food governance, we analyzed websites and documentation published by the standard owners as well as other stakeholders, drew on existing scientific studies, and conducted expert interviews with certification agencies and quality managers of supermarket chains to gather supporting evidence. The heavy reliance on information provided by the standard owners themselves may give rise to concern from a methodological perspective, of course. In the case of our inquiry, however, such a concern should only exist if we arrived at highly positive evaluations of the democratic legitimacy of the given governance institutions. After all, one would not expect the standard owners to intentionally undersell the democratic legitimacy of their

\footnotetext{
$\overline{10}$ Sometimes, participants in the debate will suggest to simply assess the effectiveness of the governance institution against its self-set objectives. This process, however, does not provide a way out of the above dilemma. After all, institutions may set objectives for themselves that neglect or even hurt the interests of those governed. In such a situation, the achievement of the self-set objectives can hardly function as a source of democratic legitimacy.
} 
institutions. As the discussion below shows, however, we do not find positive results for the democratic legitimacy of almost all of the private retail food governance institutions analyzed, when applying our criteria of participation, transparency and accountability.

\section{Participation}

Institutions of private retail food governance differ in their governance structures and roles awarded to different stakeholders. Using this difference in governance structure, one can place these institutions along a continuum ranging from retailer dominated ones, to joint retailer-producer initiatives, to multi-stakeholder initiatives. Table 2 shows how the private retail food governance institutions introduced above fall on this continuum.

Most of the retail standards presented in this paper strongly prioritise retail access. BRC, IFS, SQF, and GFSI in particular are exclusively retailer organisations, allowing other stakeholders such as food manufacturers only a consultative role.

BRC started as a pure retail standard but over the years other stakeholders became involved as well. Today, representatives from major retailers, manufacturers, certification bodies, the United Kingdom Accreditation Service (UKAS) and trade associations are involved in the development of the standard through the Technical Advisory Committee and the Standards Governance and Strategy Committee. ${ }^{11}$ It is clear, however, that British retailers still have a decisive voice since the standard is owned by BRC. Similar observations can be made about the IFS and SQF. The SQF standard is owned by FMI, an American organisation of retailers and wholesalers. The Technical Advisory council 2008-2009 has 28 members including 11 retailers and six food manufacturers, predominantly from the USA (22). ${ }^{12}$ Also in IFS, the main decision-making bodies, the Board and the International Working Group, give access to (German, French and Italian) retailers only. Other stakeholders, in particular manufacturers and certification bodies, participate in the Review Committee which has an advisory role. ${ }^{13}$

The GFSI Board of Directors, the main decision-making body, is still dominated by retailers (13 out of 16 members)

\footnotetext{
11 www.brc.org.uk/standards/default.asp?mainsection_i=1\&subsection_ $\mathrm{id}=1$ (28-3-2008); similar but not mentioning UKAS: www.brc. org.uk/standards/about_background.htm (18-02-2005). The BRC website does not provide a list of members of these committees.

12 www.sqfi.com/tac_members.htm (14-4-2009). Three members of the TAC are from Australia and 1 from Japan, UK, Canada.

13 www.ifs-online.eu (28-4-2009) Names of Review Committee members are not available on the website.
}

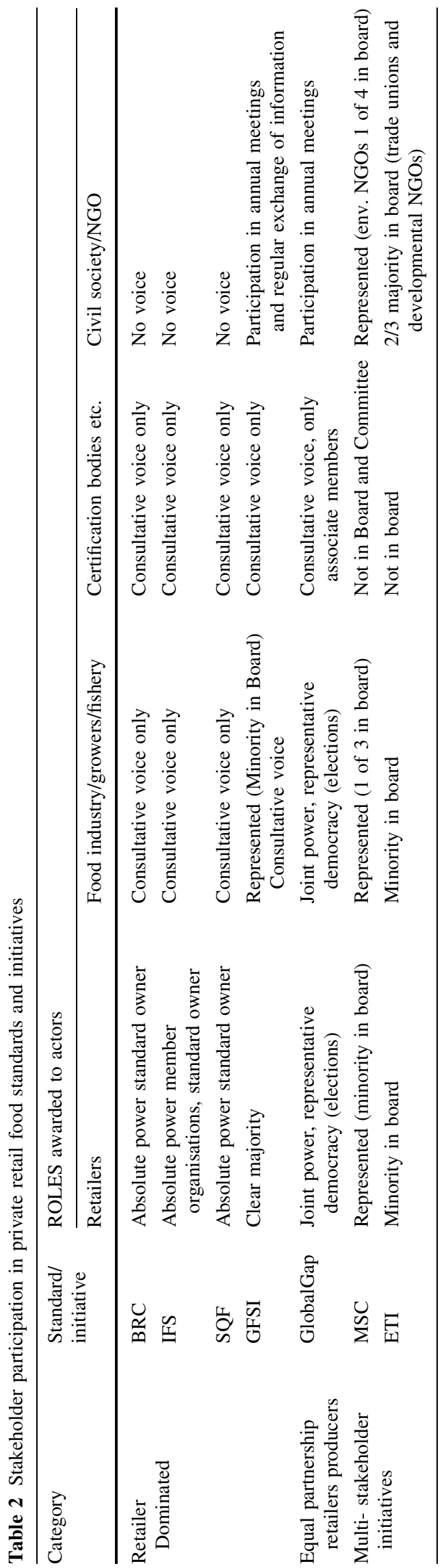


mainly from Europe and USA. ${ }^{14}$ Since September 2006 the Technical Committee, advising the Board, includes other stakeholders. Since April 2009, 60 organisations are represented in the Technical Committee including 19 retailers, 21 certification bodies, standard owners or accreditation organisation and 11 food manufacturers. ${ }^{15}$ Even there, however, most are from Europe (38) or the USA (16). Membership in the Board and Technical Committee is by invitation only.

Concluding, BRC, IFS, SQF and GFSI are dominated by retailers' organisations, allowing food industry and certification bodies to be represented in the committee that reviews the standard and makes recommendations on improvements to the Board. Consumer organisations and other NGOs are not included in the decision structure of retail standards. GFSI is the only one with some food industry representatives on the Board and with a structure for information exchange with civil society; it invites all interested parties that want a voice in GFSI to participate in annual meetings.

From 1997, EurepGap developed from a European retailer initiative into GlobalGap, a global standard, with equal participation for retailers and agricultural producers. More specifically, both the Steering Committee and the GlobaGap Sector Committees have had 50\% retailer and $50 \%$ supplier representation since 2001. GlobalGap is a membership organization. The Committees are constituted by members, elected by closed ballot of current retailer and supplier members. Each constituency elects its own representatives. Next to retailers and suppliers, associate members from the input and service side of agriculture can also participate but are not part of the decision making process. In 2009, GlobalGap still has these three different types of memberships: 42 retail and food service members (European except for 1 Japanese and 2 US), 149 producer/ supplier members (41 from outside Europe) and 100 associate members such as certification bodies, consulting and crop protection industry. ${ }^{16}$ Only 8 producer/supplier members are from Africa, 7 from Asia and 16 from Central and South America. In the sector committee for crops responsible for revising the standard, 4 out of 16 producer members are from Kenia and Brazil. The majority of both retailer and producer members in this committtee is from Europe (17 out of 25). However, in 2007 GlobalGap has started a special project to provide more opportunities for African smallholder representation in the standard setting

\footnotetext{
14 The Board has six members from Europe, seven from USA and one from China, Japan and Brazil. Three board members are from food industry (additionally two adviser members from industry). http://www.ciesnet.com (28-4-2009).

15 http://www.ciesnet.com (28-4-2009).

16 http://www2.globalgap.org (28-4-2009).
}

process. ${ }^{17}$ In addition, to facilitate GlobalGap certification for small producers it is now possible to get a group certification as a farmer group.

The ETI and MSC, finally, can be considered multistakeholder initiatives. The MSC developed from a partnership between Unilever and WWF into a multistakeholder organization. The initial governance structure of MSC (partnership between Unilever en WWF) was criticized by NGOs as lacking credibility, democratic representativity and effectiveness (Tully 2004:3). Since 2000 , the MSC is governed by the Board of Trustees comprised of global fisheries experts who approve plans, targets, strategies, financial accountability, and appoint chief board and committee members (Owens 2008). MSC is not a membership organization. Trustees are not elected but appointed by cooptation. ${ }^{18}$ Almost all trustees are from the USA, Europe or Australia (1 from Latin America), although some of them are focusing on fisheries in Africa or the Southern Ocean. Other institutional organs of the MSC include the Technical Advisory Board and the Stakeholder Council which advise the Board. In addition to the three governance bodies, committees and working groups are set up to address specific regional or topical issues. Their members come from the MSC Board, Technical Advisory Board and Stakeholder Council, and may include other experts who are invited to advise the MSC (http://www.msc.org/about-us/governance/structure). Even though the MSC has a multistakeholder governance structure, the highest decision-making authority is granted to the Board of Trustees, which is self-recruiting and functions much like a corporate board of directors, rather than a stakeholder council (Gulbrandsen 2008). Moreover, critical commentators observe discrimination in access to representatives from developing countries (Ponte 2007). Even the Stakeholder Council counts only four members in the "developing world category' (next to 11 in the 'public interest category' and 16 in the 'commercial and socioeconomic category'). ${ }^{19}$ It is further noted that only one of about ten workshops carried out since 1997 took place in a developing country (South Africa) (Ponte 2007). ${ }^{20}$ MSC has initiated efforts to overcome such criticisms by introducing special programs to improve developing countries' access to MSC certification and global sustainable seafood

\footnotetext{
${ }_{17} \mathrm{http}: / / \mathrm{www}$.africa-observer.info/ (28-4-2009).

18 In April 2009, MSC had 4 trustees from fishing industry, 3 from environmental NGOs (WWF), 3 from science, 2 from retail, 1 miscellaneous. (www.msc.org/about-us/governance/structure/boardof-trustees/whos-on-the-msc-board, 29-4-2009).

19 http://www.msc.org/about-us/governance/structure/msc-stakeholdercouncil/whos-on-the-msc-stakeholder-council (29-4-2009).

${ }^{20}$ Recently a "Sustainable Fisheries Fund" has been set up, independently from MSC, to help developing country fisheries to go through the certification process (Ponte 2007).
} 
markets, and assist small scale fisheries to gain access to data and resources needed for certification. Even though these efforts might improve market access, they do not guarantee more equal representation in decision-making processes, however. $^{21}$

The ETI includes a wide range of stakeholders in its board, as well. With board members equally spread over three caucus groups (each with 3 members on the board), ETI allows for the most participation of civil society ( 2 out of 3 member categories: trade unions and developmental NGOs). In 2007, 39 companies, four trade unions (TU) and 17 NGOs were part of the ETI (Schaller 2007). The NGOs are represented by larger organizations (e.g. Oxfam, CAFOD) and smaller, specialized NGOs (e.g. Anti-slavery International, Woman Working Worldwide), often with a focus on development or human rights issues. Among TU members are the International Trade Union Confederation (ITUC) and the International Textile, Garment and Leather Workers' Federation (ITGLWF) (ETI 2007; Schaller 2007). Concerns are voiced, however, about access constraints of developing countries due to limited resources (Schaller 2007), irregular consultation with workers (Hale 2000; Hale and Shaw 2001) and unequal power structures between UK retailers and suppliers from developing countries (Hughes 2001).

In sum, all private retail standards tend to lack democratic legitimacy from the perspective of the participation criterion to some extent. The decision-making bodies frequently do not allow participation by all groups affected by these standards. Multistakeholder initiatives can be considered more legitimate because they bring together different actors with opposing interests trying to reach an agreement on crucial societal issues. It is important to note that resource asymmetries still prevent equal participation, even if certain stakeholders are allowed participation, however. In consequence, there is a lack of sufficient participation by representatives of consumers, developing countries, and environmental and labour organizations in all private retail food governance institutions considered here. The degree of the severity of the problem clearly varies, however, with retail dominated private governance institutions reflecting the lowest degree of democratic legitimacy.

\section{Transparency}

In the cases examined here, the main source of information regarding the standards is the web. Up to date information on governance structures, membership and goals is available though some standards, especially GlobalGap, MSC

\footnotetext{
${ }^{21} \mathrm{http} / / / \mathrm{www} . \mathrm{msc}$.org/about-us/credibility/working-with-developingcountries (29-4-2009).
}

and ETI, have more extensive and detailed coverage than others. In contrast, BRC is the standard with the most limited information on its governance structure. In all cases most of the documents related to the development and monitoring of standards are only available to insiders, however. Likewise, information on the processes themselves, especially while they are going on, is rarely available. In addition, information to the general public is only provided after decisions have been made, constraining meaningful intervention from the part of civil society.

In retail dominated standards transparency tends to be selective. These standards strive for food safety while ignoring other aspects, such as environmental and social performance, which are crucial indicators for the sustainability of the food system. Performance related information, however, is available to a certain extent. Thus, an interested party can learn about the number of certified producers, for instance, and their geographical coverage. The contribution of the standards to food safety concerns is also explained; detailed statistical information on the effectiveness of standards in preventing food scares or spreading of diseases is not accessible, however. Moreover, there is no external evaluation of the standards' performance.

Equal partnership standards including environmental and social performance criteria also need to report on their performance. In that context, GlobalGap holds a series of "Success Stories" where it presents its social and market impact including the launching of new certificates, pilot projects, and corporate social responsibility initiatives. As these stories constitute selected elements they do not represent the overall GlobalGap performance, however. Moreover, similar to the previous cases such reporting is voluntary and has not undergone external evaluations.

Multistakeholder initiatives also suffer from selective transparency and performance deficiencies, but less so in relation to the other standards. MSC has been criticised, for instance, for not providing any details on catch patterns, patterns of industry adoption of practices, by-catch and habitat damage problems and individual producer activities (Iles 2007). However, since 2005 MSC has initiated an effort to undergo evaluation and report on its environmental impact while it currently collaborates with the International Social and Environmental Accreditation and Labelling (ISEAL) Alliance to explore the development of a Code of Good Practice on Measuring the Impact of Certification. ${ }^{22}$ Finally, even the ETI fails to recognize and therefore provide information on important issues such as gendered aspects of employment, as discussed earlier (Pearson 2007). Similar to the MSC, however, ETI also

\footnotetext{
${ }^{22}$ http://www.msc.org/about-us/credibility/measuring-environmentalimpacts (14-05-2009).
} 
voluntarily undergoes external evaluation of its performance. More specifically, a study completed by the University of Sussex in 2006 reveals to the public the heterogeneous impact of ETI depending on companies and type of workers (Barrientos and Smith 2006). Moreover, ETI also includes reports on pilot projects from the side of the regulatees, hosting some quite critical voices (Turner 2004). These types of transparency activities, in turn, improve the reliability of information provided by the standard owners and also enhance the standards' accountability.

Next to the web, seminars and conferences are held as well. Here openness and availability of information also differs among the standards. More specifically, those with strong retail participation (e.g. BRC, SQF, and IFS) allow access only to members. GFSI allows participation of other stakeholders, such as other companies' executives as well as suppliers' senior sales and marketing management personnel. In contrast, GlobalGap, MSC and ETI are open to the public upon registration. Moreover, they allow access to minutes of conferences, round tables and short video archives. ETI and MSC also publish information on their board meetings. However, in those cases too no protocols of caucus group meetings are available (see also Schaller 2007).

The language used is mostly non-technical facilitating the comprehensibility of information. The majority of sources is in English, although all standards are translated into other languages. Thus, BRC is translated into fifteen languages, such as Arabic, Chinese, Thai and many European languages. Likewise, $\mathrm{SQF}$ is also translated into Spanish. Some standards also include information in additional languages in their websites. Thus, next to English, GFSI also has reports in French, Spanish, Japanese and Chinese. Likewise, IFS reports in English, German, French and Chinese. GlobalGap publishes information in a number of European (Dutch, English, French, German, Greek, Italian, Portuguese, and Spanish) and non-European (Turkish and Thai) languages. MSC includes information in English, French, German, Spanish, and Chinese. Finally, ETI publishes some documents in Spanish and Chinese as well, while further translations are expected to follow (Schaller 2007). One may question, of course, whether the predominance of European languages really facilitates access for all affected stakeholders, especially farmers in developing countries.

In sum, transparency increases as participation broadens. Retailer dominated standards are less open about their processes and have limited issue coverage. Moreover, information provision is voluntary and based on selfreports. In contrast, standards involving more stakeholders are relatively more transparent. Detailed information on governance structures, membership and projects is available on the web. Moreover, conferences and seminars are open to all and relevant information is published on the web, even though board and/or caucus group meetings are not made public. Even in multistakeholder initiatives, however, transparency tends to be selective in its sustainability coverage. Yet, the reliability of information is higher due to external evaluations of the standards' performance, thus also improving the standards' accountability.

\section{Accountability}

In all cases examined in this paper, stakeholders need to report on their activities on a somewhat regular basis. Supermarkets need to report to their boards and board members to their constituencies, while trade union and civil society representatives are also accountable to their organisations. Thus, the standards provide a basis for internal accountability. The extent to which peer pressure actually is used to ensure compliance may differ, of course. However, this is a question on which little information is publicly available.

We do not find critical differences among the standards regarding external evaluations of accountability in the narrow sense. Many private food standards rely on third party certification for monitoring and enforcing compliance with the standard. A company wishing to be certified against BRC, IFS, GlobalGap or MSC, e.g. appoints an accredited certification body to audit the company. The certification bodies have to be accredited by independent accreditation bodies to certify against the standards. With the exception of SQF, the standard owners do not decide which organisations are authorized to monitor and enforce compliance with the standard. Usually a certified company is audited at least once a year. Some standards also require or allow unannounced audits. An audit report has to be technically reviewed prior to the certification decision by the certification body. The person or body deciding to grant, suspend, revoke or renew certification should be independent to the auditor. Critical or major non-conformity against fundamental requirements of the standard should result in suspending or withholding the certification, and a new audit has to begin. Minor non-conformities are followed by corrective action and need to be revisited.

Again, little information on the extent to which these mechanisms prevent non-complying companies from becoming certified is available. Moreover, critical observers point out weaknesses of third-party certification mechanisms. Thus, the certification bodies also participate in consulting meetings, working groups, and so on. In most of the cases, the certification organisations are trained by the standard owners, while the methodology used in the certification process is considered intellectual property 
right of the standard, and thus details remain confidential. In addition, the company wishing to be certified hires the certification organisation itself which could provide an incentive to forego rigour in favour of future cooperation with the company. Finally, the quality of third-party audits is not always ensured. In the case of ETI, for instance, members are concerned about the increase of fraudulent practices in auditing, such as the keeping of false records (common practice particularly in China) or instructing workers to provide false information (ETI 2006).

More fundamentally, third party certification mechanisms only aim to ensure compliance with the standard and thus accountability on the issues covered by the standard at the most. Even in these cases, the question is to whom accountability is provided. After all, not everyone affected by the standard has paths and instruments available to demand compliance in the case of private retail standards. In the case of multi-stakeholder initiatives, the group able to demand accountability is by definition broader. Such initiatives also have mechanisms by which workers and suppliers can hold the standards accountable to a certain extent. Thus, ETI provides an "Alleged Code Investigation Guidelines" which allows NGOs and TU to forward complaints from Southern members (ETI 2001). Moreover, ETI member companies commit to provide secret complaint mechanisms for workers even though few have actually done so (Turner 2004).

Yet, the analysis of the distribution of participation above shows that even in multi-stakeholder initiatives not all groups potentially affected by private food governance institutions are represented. Moreover, the difficulties in attaining transparency from a developing country perspective reinforce access inequality. The effectiveness of ETI investigation guidelines, for instance, depends on workers knowing about them, but only few workers have that knowledge in reality (Schaller 2007). Publication of external evaluations of standards' performance could improve accountability to the general public. Again, these evaluations are made on the basis of the standards' own terms of references and do not cover externalities or unintended consequences. In sum, external accountability of retail standards is fundamentally limited and accountability, as such, cannot serve as a reliable source of democratic legitimacy.

The picture with respect to the accountability of private retail food governance is mixed, then. Internal and even narrowly defined external accountability frequently exist. Indeed, peer-review mechanisms or auditing of standards is a feature of most of the standards and initiatives considered here. Yet, accountability to the broad range of affected stakeholders is given in hardly any institution. In terms of this broader notion of accountability, then, private retail food governance institutions tend to exhibit little democratic legitimacy.

\section{Conclusions}

In this paper, we analyzed the democratic legitimacy of private retail food governance, using the criteria of participation, transparency and accountability. We pursued this investigation due to the highly ambivalent implications that private retail food governance exhibits for the sustainability of the global agrifood system. In our analysis, we found that the criteria of participation, transparency and accountability are entirely fulfilled in none of the cases. In terms of participation, we identified a lack of access in the development and monitoring of private standards, especially for civil society actors and small farmers and fishermen, particularly from the South, as an area of high concern. Interestingly, this is the case even in broad multistakeholder standards and initiatives, such as ETI and MSC, which frequently tend to have a better image in the public (and even in the scientific) debate. Even here, financial and technological constraints impede the participation of resource weak actors, however. Moreover, the power asymmetries among the actors involved in private retail food governance raise questions about the constraints on actors' choice sets even if they are allowed to participate. In terms of transparency, we found that it is limited in its external dimension, thus weakening the influence of actors besides the standard owners. However, differences exist between the standards, with multistakeholder initiatives being considerably more open and reliable in their reporting. Finally, when it comes to accountability, we noted that even though internal accountability is provided in most cases, external accountability to the general public is either lacking or in need of major improvement.

Indeed, the asymmetries in access and influence between the different stakeholders highlighted by an analysis of the three democratic criteria constitute one of the core challenges for private food governance and exercise an impact not just on the criterium of participation, but also on questions of transparency and accountability. The asymmetries in access and influence are also likely to contribute to the mixed impact on the sustainability of the global agrifood system that was pointed out earlier. Given the existence of such asymmetries, it should not come as a surprise that most private food standards primarily reflect the interests of retailers in minimizing the risk of scandals and marketing their products to Northern consumers. Therefore, the emphasis rests on food safety and traceability. Some environmental and worker welfare issues are included as well, as Northern consumers place increasing demands on retailers in this context. The lack of an adequate inclusion of civil society organizations in the retail dominated schemes, however, means that the standards tend to address these issues only in a selective manner. Finally, small farmers in the South have little 
representation in the decision-making bodies of most of the private food governance institutions discussed here and no means to enforce a pursuit of their interests either.

Some of the initiatives discussed do recognise the power asymmetry between the rich world and farmers in developing countries, however. Both GlobalGap and MSC have pilot programs supporting small producers in developing countries to overcome financial, educational and other barriers to certification. Even though such initiatives are welcome, they tend to be the exception rather than the rule. Moreover, it will take time to evaluate whether such efforts constitute effective and sufficient measures to overcome critical societal concerns.

The result of our analysis of the democratic legitimacy of private retail food governance, then, is not an optimistic one. Private food governance may be desirable in a number of ways. Thus, it has been connected to some improvements in food safety and quality and even to some extent environmental conditions were achieved. Yet, its potential negative consequences, for instance in terms of the marginalization of millions of small farmers in developing countries, are sufficiently severe to remind us of the importance of participation, transparency and accountability in its creation as well as the need for checks and balances on the power exercised by the different actors involved, especially the large retail corporations.

Again, establishing institutions that will fulfil the criteria of participation, transparency, and accountability in global food governance is extremely difficult. As pointed out above, public governance is far from perfect in this respect and one may wonder if it matters to small farmers in the South if they lose their livelihoods due to regulations introduced by the EU or US government or due to the GlobalGap. In other words, global public food governance clearly warrants critical questions regarding its democratic legitimacy as well. Yet, the dramatic expansion in private retail food governance, the structural power behind it, and its severe social implications highlight the urgent need to improve the situation. Due to the obligatory quality private standards assume and their global coverage, the legitimation of private food governance becomes a fundamental concern for global governance. Standards and certification mechanisms need to be established in a global market with huge information asymmetries, complex production chains and distancing between production and consumption choices. Yet, the development and monitoring of standards affecting a multitude of actors in a multitude of locations, needs to take place in a context where mechanisms of participation, transparency and accountability are enforced and fortified.

From a democratic perspective, it is crucial to remember that the institutionalization of new forms of governance at the global level is a development in progress. The institutionalization and perfection of these forms does not happen automatically or overnight. Instead, it requires constant attention and discussion both at the national and global levels. It is the responsibility of (democratically elected) governments worldwide to foster arenas where disputes and contestations of inadequate forms of governance can take place. The presence of such arenas constitutes, in turn, the seed of all democratic transformations.

Open Access This article is distributed under the terms of the Creative Commons Attribution Noncommercial License which permits any noncommercial use, distribution, and reproduction in any medium, provided the original author(s) and source are credited.

\section{References}

Aalders, Marius, and Ton Wilthagen. 1997. Moving beyond command and control: Reflexivity in the regulations of occupational safety and health and the environment. Law and Policy 19: 415444.

ActionAid International. 2005. Power hungry. Six reasons to regulate global food corporations. London: ActionAid International. www.actionaid.org.uk/_content/documents/power_hungry.pdf. Accessed 23 June 2007.

Baines, Richard. 2005. Private sector environment standards: Impact on ecological performance and international competitiveness of UK agriculture. Final Report RES-224-25-0036. Newcastle: University of Newcastle. http://www.relu.ac.uk/research/ projects/Baines.htm.

Barrientos, Stephanie and Sally Smith. 2006. The ETI code of labour practice: Do workers really benefit? Main findings and recommendations from an independent assessment for the Ethical Trading Initiative. Sussex: University of Sussex.

Barrientos, Stefanie, Catherine Dolan and, Anne Tallontire. 2001. The gender dilemma in ethical trade. NRI working paper no 2624. Chatham: Natural Resources Institute.

Black, Julia. 2002. Critical reflections on regulation. London: CARR Discussion Paper Series.

Blowfield, Michael. 2005. Corporate social responsibility-The failing discipline and why it matters for international relations. International Relations 19: 173-191.

Braithwaite, John. 1982. Enforced self-regulation: A new strategy for corporate crime control. Michigan Law Review 80: 1466-1507.

Brown, Oli and Christina Sander. 2007. Supermarket buying power: Global supply chains and smallholder farmers. Winnipeg: IISD. http://www.tradeknowledgenetwork.net/pdf/tkn_supermarket. pdf. Accessed 31 Oct 2008.

Brühl, Tanja. 2002. The privatisation of international environmental governance. In Proceedings of the 2001 Berlin conference on the human dimensions of global environmental change, ed. Frank Biermann et al., 371-380. Potsdam: Global Environmental Change and the Nation State.

Busch, Lawrence. 2000. The moral economy of grades and standards. Journal of Rural Studies 16: 273-283.

Clapp, Jennifer, and Doris Fuchs. 2009. Corporate power in global agrifood governance. Boston: MIT Press.

Coglianese, Cary, and David Lazer. 2003. Management-based regulation. Prescribing private management to achieve public goals. Law and Society Review 37: 691-730.

Conca, Ken. 2001. Consumption and environment in a global economy. Global Environmental Politics 1(3): 53-79.

Conzelmann, Thomas, and Klaus Dieter Wolf. 2008. The potential and limits of governance by private codes of conduct. In 
Transnational private governance and its limits, ed. JeanChristophe Graz, and Andreas Nölke, 98-114. New York: Routledge/ECPR studies in European Political Science.

Dryzek, John S. 1990. Discursive democracy: Politics, policy and political science. Cambridge: Cambridge University Press.

Erman, Eva, and Anders Uhlin. forthcoming. Legitimacy beyond the state? re-examining the democratic credentials of transnational actors. New York: Palgrave.

ETI. 2001. ETI Alleged code violation investigation guidelines. http:// www.ethicaltrade.org/resources/key-eti-resources/eti-alleged-codeviolation-investigation-guidelines Accessed 26 Nov 2008.

ETI. 2006. Getting smarter at auditing. Tackling the growing crisis in ethical trade auditing. Report from ETI members' meeting 16 November 2006, (http://www.ethicaltrade.org/Z/lib/2006/11/ smart-audit/index.html. Accessed 26 Nov 2008.

ETI. 2007. About the ethical trading initiative. Report from ETI members' meeting, http://www.ethicaltrade.org/Z/lib/annrep/ 2007/en/index.shtml. Accessed 26 November 2008.

Fuchs, Doris. 2007. Business power in global governance. Boulder: Lynne Rienner.

Fuchs, Doris and Agni Kalfagianni. 2009. The democratic legitimacy of private authority in the food chain. In The challenges of global business authority: Democratic renewal, stalement or decay? eds. Tony Porter and Karsten Ronit. New York: SUNY Press.

Fuchs, Doris, Agni Kalfagianni, and Maarten Arentsen. 2009. Retail power, private standards and sustainability in the global food system. In Corporate power in global agrifood governance, eds. Jennifer Clapp and Doris Fuchs. Boston: MIT Press.

Fulponi, Linda. 2006. Private voluntary standards in the food system: The perspective of major food retailers in OECD countries. Food Policy 31: 1-13.

Furger, Franco. 1997. Accountability and systems of self-governance: The case of the maritime industry. Law and Policy 19: 445-476.

GlobalGap. 2008. Control points and compliance criteria propagation material. http://www.globalgap.org/cms/front_content.php? idcat $=49$. Accessed 11 May 2009.

Gulbrandsen, H.Lars. 2008. Accountability arrangements in non-state standards organisations. Organization 15: 563-583.

Gunningham, Neil, and Darren Sinclair. 1999. Regulatory pluralism: Designing policy mixes for environmental protection. Law and Policy 21: 49-76.

Hale, Angela. 2000. What hope for 'ethical' trade in the globalised garment industry? Antipode 32(4): 349-356.

Hale, Angela, and Linda M. Shaw. 2001. Women workers and the promise of ethical trade in the globalised garment industry: A serious beginning? Antipode 33(3): 510-530.

Havinga, Tetty. 2006. Private regulation of food safety by supermarkets. Law and policy 28(4): 515-533.

Heiskanen, Eva, and Mika Pantzar. 1997. Toward sustainable consumption: Two new perspectives. Journal of Consumer Policy 20(4): 409-442.

Held, David. 1995. Democracy and the global order. Stanford: Stanford University Press.

Hughes, Alex. 2001. Multi-stakeholder approaches to ethical trade: Towards a reorganisation of UK retailer's global supply chains? Journal of Economic Geography 1: 421-437.

Hutter, M.Bridget. 2001. Regulation and risk. Occupational health and safety on the railways. Oxford: Oxford University Press.

Iles, Alastair. 2007. Making the seafood industry more sustainable: Creating production chain transparency and accountability. Journal of Cleaner Production 15: 577-589.

Jaffee, Steven and Spencer Henson. 2004. Standards and agrofood exports from developing countries: Rebalancing the debate. Policy research paper no. 3348. World Bank. Washington.

Kalfagianni, Agni. 2006. Transparency in the food chain. Twente: University of Twente Press.

Keohane, Robert. 2006. Accountability in world politics. Scandinavian Political Studies 29(2): 75-87.

Lang, Tim and David Barling. 2007. The environmental impact of supermarkets: Mapping the terrain and policy problems in the UK. In Supermarkets and agri-food supply chains, ed. David Burch and Geoffrey Lawrence. Cheltenham: Edward Elgar.

Leadbitter, Duncan, Guillermo Gomez, and Frazwer McGilvray. 2006. Sustainable fisheries and the East Asian seas: Can the private sector play a role? Ocean and Coastal Management 49: 662-675.

Newman, Janet. 2001. Modernising governance. New labor, policy and society. London: Sage.

Owens, C. Matthew. 2008. Sustainable seafood labeling: An analysis of the marine stewardship council. Graduate School of international relations and pacific studies. University of California, San Diego, IR/PS Case \# 07-02 http://irps.ucsd.edu/assets/021/8419. pdf Accessed 10 November 2008.

Pearson, Ruth. 2007. Beyond women workers: Gendering CSR. Third World Quarterly 28(4): 731-749.

Ponte, Stefano. 2007. Greener than thou: The political economy of fish ecolabelling and its local manifestations in South Africa. World Development 36(1): 159-175.

Porter, Tony, and Karsten Ronit (eds.). 2010. The challenges of global business authority: Democratic renewal, stalement or decay?. New York: SUNY Press.

Reardon, Thomas, Jean-Marie Codron, Lawrence Busch, James Bingen, and Craig Harris. 2001. Global change in agrifood grades and standards: Agribusiness strategic responses in developing countries. International Food and Agribusiness Management Review 2(3): 421-435.

Robison, Wade L. 1984. Management and ethical decision making. Journal of Business Ethics 3(4): 287-291.

Schaller, Susanne. 2007. The democratic legitimacy of private governance: An analysis of the ethical trading initiative. INEF Report 91/2007, Institute for Development and Peace, University of Duisburg-Essen.

Scharpf, W.Fritz. 1998. Demokratie in der transnationalen Politik. In Politik der globalisierung, ed. Ulrich Beck, 228-253. Frankfurt/ Main: Suhrkamp.

Sinclair, Darren. 1997. Self-regulation versus command and control? Beyond false dichotomies. Law and Policy 19: 529-559.

Smith, Sally, and Stephanie Barrientos. 2005. Fair trade and ethical trade: Are there moves towards convergence? Sustainable Development 13: 190-198.

Tully, Stephan. 2004. Access to justice within the sustainable development self-governance model. London: CARR Discussion Paper Series.

Turner, Jane. 2004. Voices from the South and Eastern Europe. Consultation report on ethical trade for rge ETI NGO Caucus. http://www.eti2.org.uk/Z/lib/2004/05/ngo-report/ETIvoicesfromSouth.pdf. Accessed 14 May 2007.

Van der Grijp, Nicolien. 2008. Regulating pesticide risk reduction: The practice and dynamics of legal pluralism. Amsterdam: Vrije Universiry of Amsterdam.

Van der Grijp, M. Nicolien, Terry Marsden, and Josefa S.B. Cavalcanti. 2005. European retailers as agents of change towards sustainability: The case of fruit production in Brazil. Environmental Sciences 2 (4): 445-460.

Van Kersbergen, Kees and Frans, Van Waarden. 2001. Shifts in governance: Problems of legitimacy and accountability. The Hague: NWO. 


\section{Standards' websites}

BRC: http://www.brc.org.uk/

IFS: http://www.ifs-online.eu/

SQF: http://www.sqfi.com/

GFSI: http://www.ciesnet.com/

GlobalGap: http://www.globalgap.org/

MSC: http://www.msc.org/

ETI: http://www.ethicaltrade.org/

\section{Author Biographies}

Doris Fuchs is Professor of International Relations and Development Politics at the University of Münster. She has recently co-edited Corporate Actors in Global Agrifood Governance (MIT Press 2009) with Jennifer Clapp and published Business Power in Global Governance (Lynne Rienner 2007) as well as Institutions for Environmental Stewardship (Kluwer Academic Publishers 2003). She works on issues of environmental and food governance, addressing the question of the effectiveness and legitimacy of private governance and the implications of institutional structures and processes. Moreover, she explores the politics of transparency in the food chain, the determinants of the sustainability of food consumption, and the potential for sustainable consumption governance in the food sector. She has published articles in Global Environmental Politics, Millenium-Journal of International Studies, Journal of Consumer Policy, Energy Policy, International Interaction, and Business Strategy and the Environment.
Agni Kalfagianni is lecturer at the University of Stuttgart, chair of International Relations and European Integration. She holds a diploma on Environmental Science from the University of the Aegean, an MSc on Environmental Economics from the University of York, and a PhD from the University of Twente, Centre for Clean Technology and Environmental Policy. Agni has worked on the role of private and public actors in fostering sustainability and transparency in the food chain at the European and national (Dutch) levels. She has also published articles on corporate social responsibility strategies in European food and agricultural governance. Her main research interests include environmental policies and politics, sustainable development, environmental ethics and democratic governance.

Dr. ir. Tetty Havinga is a senior researcher and lecturer at the Institute for the Sociology of Law of the Radboud University Nijmegen, The Netherlands. She studied sociology at Wageningen University and obtained her PhD in 1989 with a study on Labour Offices and Collective Dismissal in the Netherlands. She published on the regulation of food safety, policy implementation and law enforcement, equal opportunities, and the relationship between migrants and the law. Tetty is interested in relations between industry and law with a view to the public interest. Her current research projects deal with the development and effects of private regulation of food safety and the experiences of large companies with Dutch special courts. 